\title{
PULSE-ECHO PHASED ARRAY ULTRASONIC INSPECTION OF PULTRUDED ROD STITCHED EFFICIENT UNITIZED STRUCTURE (PRSEUS)
}

\author{
P. H. Johnston
}

NASA Langley Research Center, Hampton, VA 23681

\begin{abstract}
A PRSEUS test article was subjected to controlled impact on the skin face followed by static and cyclic axial compressions. Phased array ultrasonic inspection was conducted before impact, and after each of the test conditions. A linear phased array probe with a manual X-Y scanner was used for interrogation. Ultrasound showed a delamination between the skin and stringer flange adjacent to the impact. As designed, the stitching in the flange arrested the lateral flaw formation. Subsequent ultrasonic data showed no delamination growth due to continued loading.
\end{abstract}

Keywords: Phased Array, Ultrasonics, Composites, Out-of-Autoclave

PACS: $81.70 .-\mathrm{q}$, 81.70.Cv, 43.35.Zc

\section{INTRODUCTION}

The Pultruded Rod Stitched Efficient Unitized Structure (PRSEUS) structural concept is under development by NASA and the Boeing Company, in conjunction with the Air Force Research Laboratory, under the Subsonic Fixed Wing (SFW) Project of the Fundamental Aeronautics Program. PRSEUS was also offered for consideration by the Advanced Composites Technology (ACT) Project as a candidate structural concept for large rocket booster applications, such as the proposed Ares V booster. As part of the structural concept down-select process for ACT, a multi-Center NDE team was charged with ranking the "inspectability" of the various structural concepts under consideration. At that time, none of the team members had any experience with PRSEUS, but did have experience with earlier stitched and out-of-autoclave composite structures. When the opportunity arose to perform ultrasonic inspection of a PRSEUS panel during the course of load testing, it was recognized as work which combined NDE support for SFW testing and hands-on input for ACT concept assessment.

\section{PULTRUDED ROD STITCHED EFFICIENT UNITIZED STRUCTURE (PRSEUS)}

The PRSEUS concept, depicted in Fig. 1, has been developed as a low-cost, lightweight composite structure for aircraft [1,2], which offers advantages over traditional 
metallic structure. The PRSEUS concept is comprised of a stitched carbon-epoxy material system with the potential for reducing the weight and cost of transport aircraft structure by eliminating fasteners, thereby reducing part count and labor. By adding unidirectional carbon rods to the top of stiffeners, the panel becomes more structurally efficient. This combination produces a more damage tolerant design.

Some key features of the PRSEUS concept are: the improved stiffness provided by the pultruded rod; the crack-arresting nature of the stitches, which enables the use of failsafe design principles; reduced tooling size and weight enabled by the self-supporting nature of the stitched preform; and improved resin infusion through the use of Controlled Atmospheric Pressure Resin Infusion (CAPRI).

\section{MECHANICAL TEST SEQUENCE}

The panel tested in this study was similar to that shown in the photograph in Fig. 1, comprising a flat panel with seven stringers and four frames. The dimensions of the exposed panel were 42.3" wide X 78.5" long (after potting the ends for compression loading). The sequence of NDE and mechanical load testing was:

- Perform baseline NDE survey of panel

- Perform impact near the panel center (45 ft lb using a $25 \mathrm{lb}$ drop weight impactor with a 1 inch diameter spherical tup)

- Post-impact NDE of impact area

- Instrument the panel with strain gages

- Repeat post-impact NDE of impact area (instrumented, on load frame)

- Perform static compression load to design limit load (137,000 lb)

- Perform post-static load NDE of impact area

- Cycle in compression 20 times to approximately 96,000 lb

- Perform post-cyclic load NDE of impact area

- Static compression load to failure (expected at approximately 200,000 lb)

\section{ULTRASONIC MEASUREMENT APPROACH}

The flat surface of the PRSEUS panel provided a good interface to use a linear ultrasonic array with a solid plastic wedge, attached to a manually-operated X-Y encoder fitted with suction cups, as shown in Fig. 2. An area of approximately 20 " X 20 " could be inspected in approximately 20 minutes, including the time for positioning the scanner. A 10 $\mathrm{MHz}$ linear phased array (64 elements, each $10 \mathrm{~mm} \mathrm{X} 0.5 \mathrm{~mm}$ ) was used with an aperture of 16 elements. A zero-degree wedge was employed, and the beam was directed straight down, focused approximately $2 \mathrm{~mm}$ below the surface of the composite. Water was sprayed on the panel surface to complete acoustic coupling.

When the panel was instrumented with strain gages, however, the gages, wires and tape presented physical obstacles for coupling the $2.5 " \mathrm{X} 1.13$ " solid wedge. A captive water column probe with a flexible membrane, which can accommodate relatively small perturbations on the surface, enclosing a 10MHz, 64-element ( $7 \mathrm{~mm}$ X $0.6 \mathrm{~mm}$ ) immersion style linear array, was used for the scans performed after instrumentation of the panel. The two probes are depicted schematically in Fig. 2. 

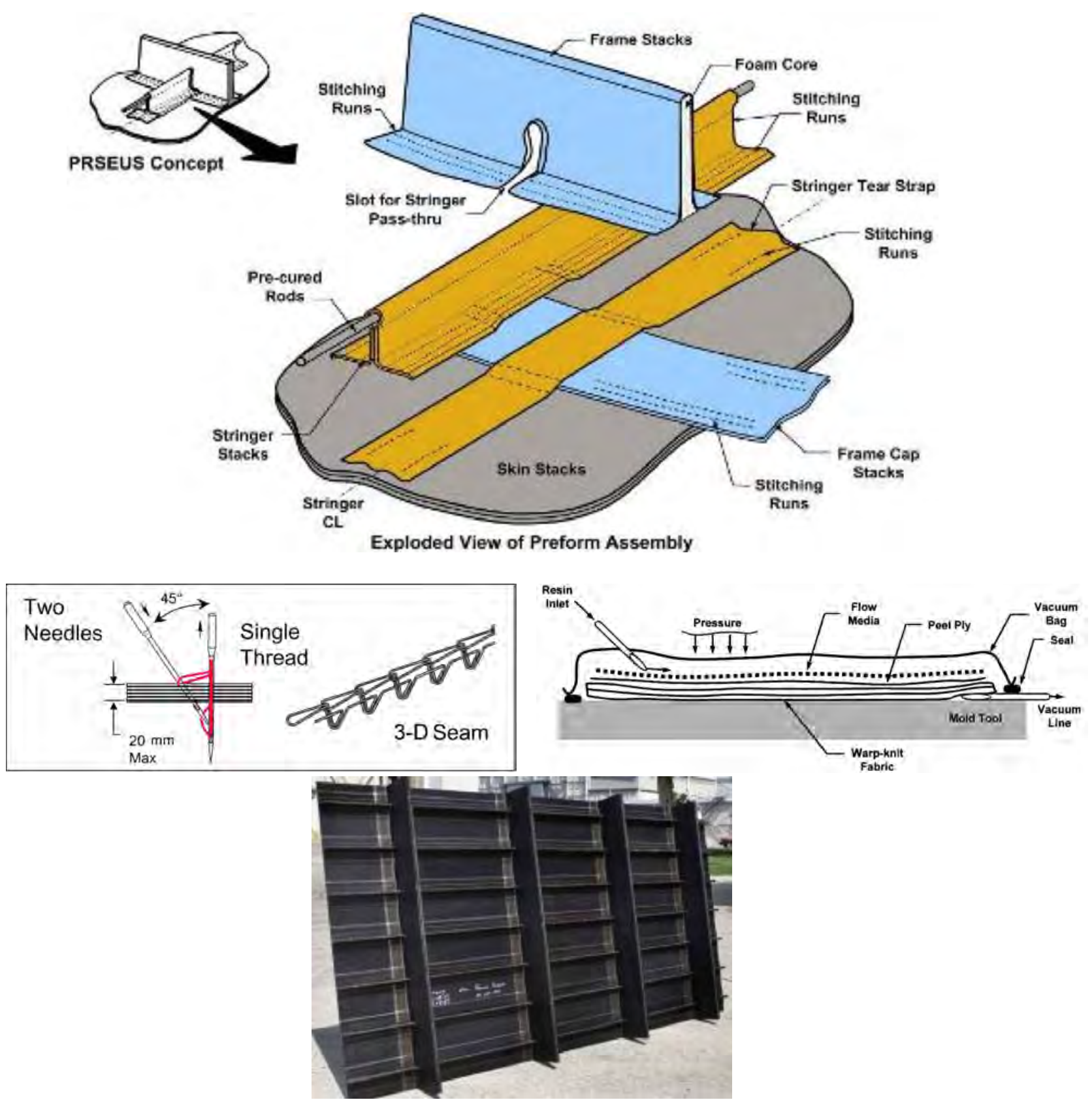

FIGURE 1. The PRSEUS dry preform is built up from carbon fabric stacks for the frame, stringers and skin. The layers are stitched together with Vectran fibers, using a single-sided sewing method, then bagged and infused with resin [1].

\section{ULTRASONIC DATA AND RESULTS}

A-scan data were acquired at each point over the area. The geometry presented four distinct thicknesses of composite, as depicted in Fig. 3. The thinnest was the skin plies only, designated as A. The second thickest was over the stringer flanges, designated C. Sites over the frame flanges (B) and the overlap of the stringer flange fabric over the frame flanges (D) were the thickest areas. In order to display C-scan data, we applied depth gates to select the echoes of interest. Gate A selects only the echoes arriving near the time of the 
skin back wall echo. Gate $\mathrm{C}$ selects the stringer flange back wall. A wide-open gate, designated A-D, includes echoes returning from all depths.

\section{Comparison of Baseline to Post-Impact}

Figure 4 compares $\mathrm{C}$-scans from the baseline data (left column) with data taken after the impact was performed (right column). The top row is Gate A-D, plotting the peak echo from any depth. The webs of the stringers and the frames are echo-free, as can be expected. There is higher attenuation along the rows of stitching, but the signal is still measureable. There is also loss of echo at the edges of the flanges, where the back surface tapers. Comparing the post-impact images with the baseline, one sees a lower-echo region

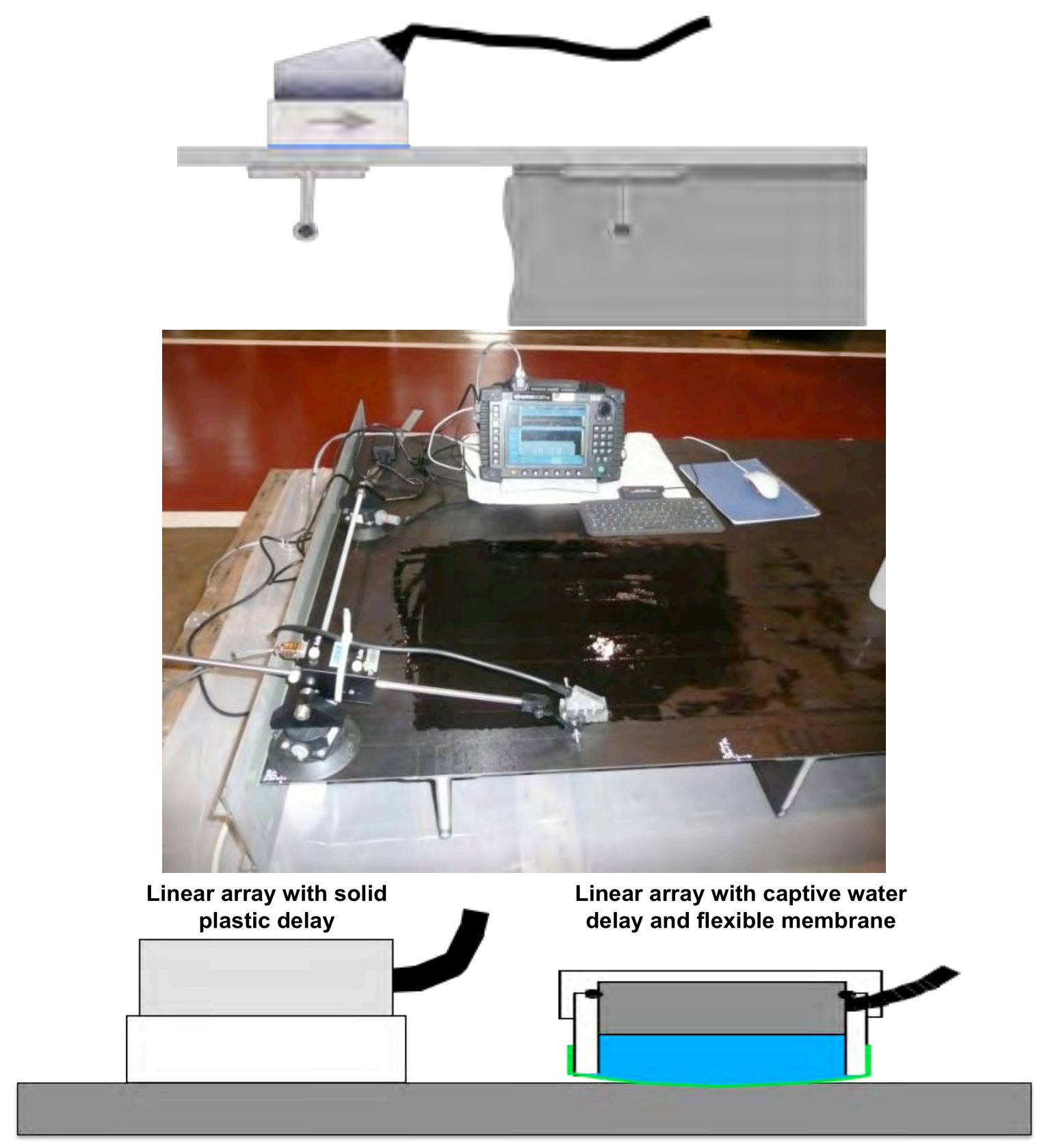

FIGURE 2. A linear ultrasonic array coupled to a manual X-Y encoder was used to interrogate the PRSEUS panel. Before installation of gages, a solid plastic wedge could be used. In order to better accommodate the presence of wires, gages and tape, a captive water column with flexible face was used after instrumentation. 


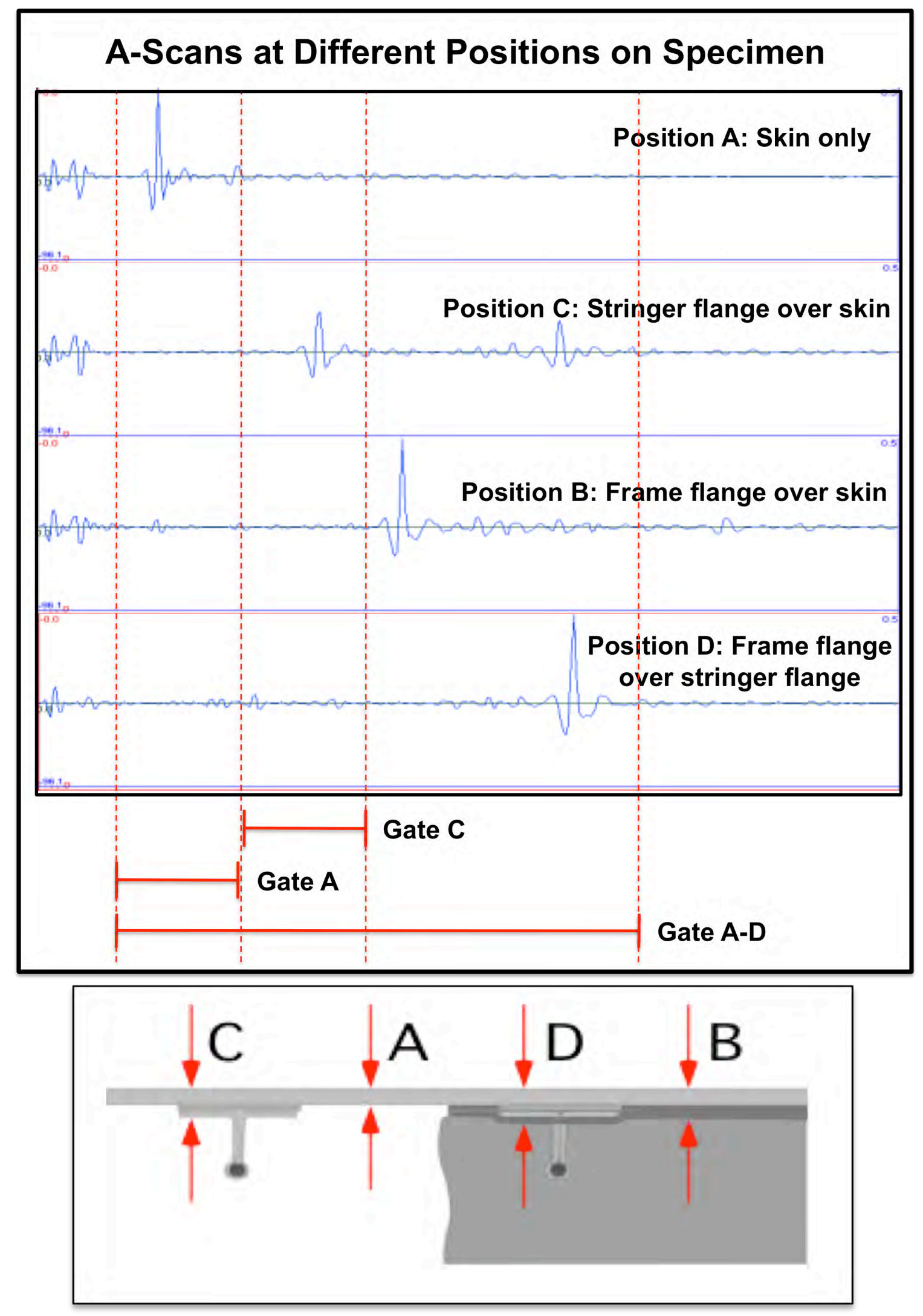

FIGURE 3. A-scan results from each of the four thicknesses presented by PRSEUS. Position A: skin only. Position B: skin and frame flange. Position C: skin and stringer flange. Position D: skin, frame flange and stringer flange. Depth gate A selects echoes from skin back wall. Gate $\mathrm{C}$ selects echoes from back wall of stringer flange. Gate A-D passes echoes from all depths. 
in the center, which corresponds to the site of the impact.

Moving to Gate A yields only echoes at the depth of the back surface of the skin. Comparing the C-scans in the middle row of Fig. 4, one sees the rectangular areas of flange-free skin, and in the post-impact image there appears an area of delamination under the stringer flange to the left of the impact site. Measurements show the delamination extends 4.39" above and 4.28" below the impact center, but the lateral dimension was constrained by the flange stitches to 0.83 " width.

The bottom row of Fig. 4 shows the C-scans derived from Gate $C$, at the stringer flange back wall. Again, evidence of the delamination appears, but as an echo-free area matching the size, shape and location of the delamination echo in the middle row.

\section{$\underline{\text { Results Following Static Load and Cyclic Load }}$}

Figure 5 compares data taken in the load frame after the panel was compressed to static limit load (left column) and after the panel saw an additional 20 cycles of compression (right column). A photograph of the instrumented surface (prior to application of speckle paint) is presented at the bottom for comparison. The arrow is directed toward the point of impact. Data for Gate A (top row) and Gate C (middle row) are presented.

The data show that the flexible face captive water probe works reasonably well in this setting, permitting the probe to move over gages, some wires, and tape while maintaining coupling around them. Because the probe casing had not been designed to work with the X-Y scanner, there was an occasional small slip of the probe in the grips.

Comparing the data in Fig. 5 with that in Fig. 4, one can see that the delamination did not change size or shape during the application of static and cyclic loading.

\section{SUMMARY}

Manually-acquired contact ultrasonic phased array NDE showed that the delamination caused by impact in the PRSEUS panel was constrained by the flange stitches, as designed. In addition, the delamination did not grow in length or width during application of design limit compression load or subsequent cyclic compression loading. Measurements showed that contact pulse-echo ultrasound works well for PRSEUS, and demonstrated the effective use of a flexible face captive water column array probe.

\section{ACKNOWLEDGEMENTS}

This work was jointly supported by Subsonic Fixed Wing and Advanced Composites Technology, and utilized technology developed for Aircraft Aging and Durability and Composite Crew Module. Travel support was from Environmentally Responsible Aviation.

\section{REFERENCES}

1. A. Velicki, "Damage Arresting Composites for Shaped Vehicles," NASA-CR-2009215932, (2009).

2. D. Jegley, "Experimental Behavior of Fatigued Single Stiffener PRSEUS Specimens," NASA-TM-2009-215955, (2009) 
BASELINE
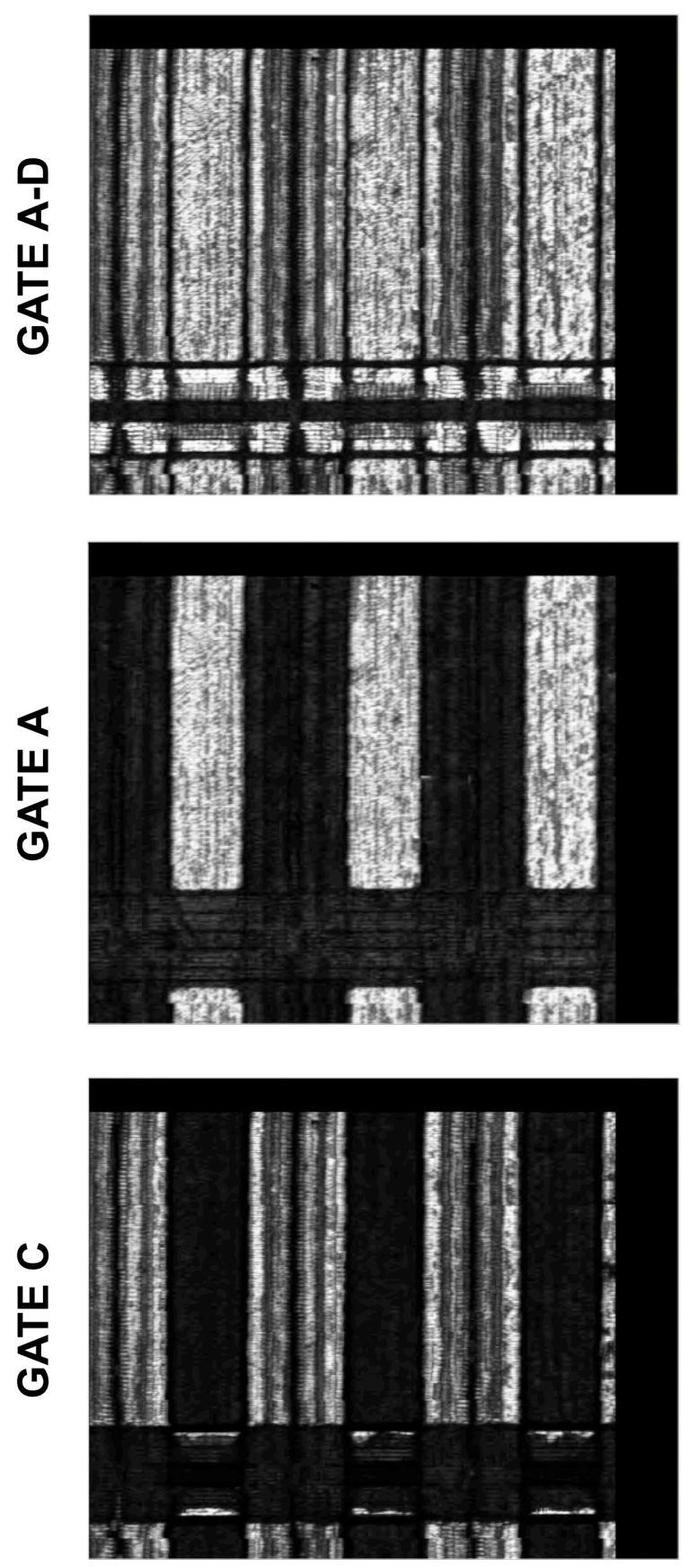

POST-IMPACT
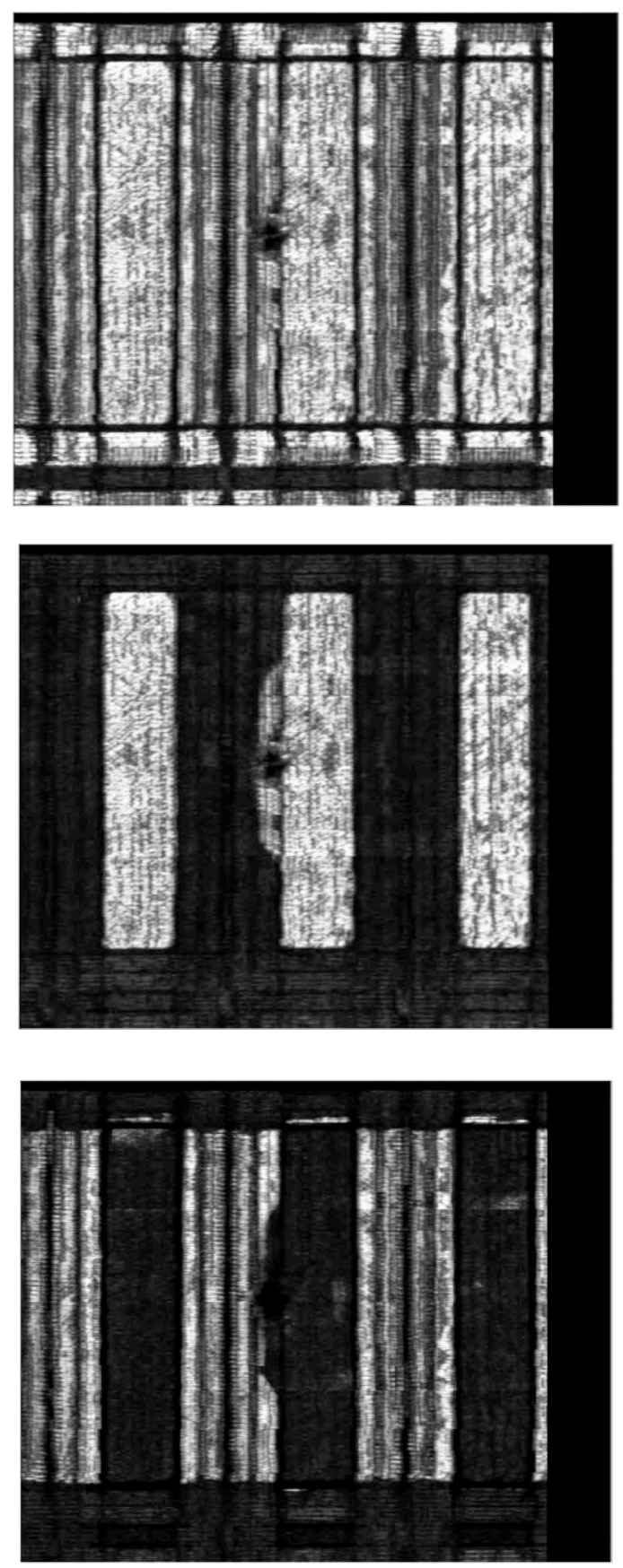

FIGURE 4. C-scan results comparing baseline state to post-impact condition of panel. Each row represents data from gates defined in Fig. 3. A delamination caused by the impact is observed under the stringer flange, which is laterally constrained by the stitching in the flange. 

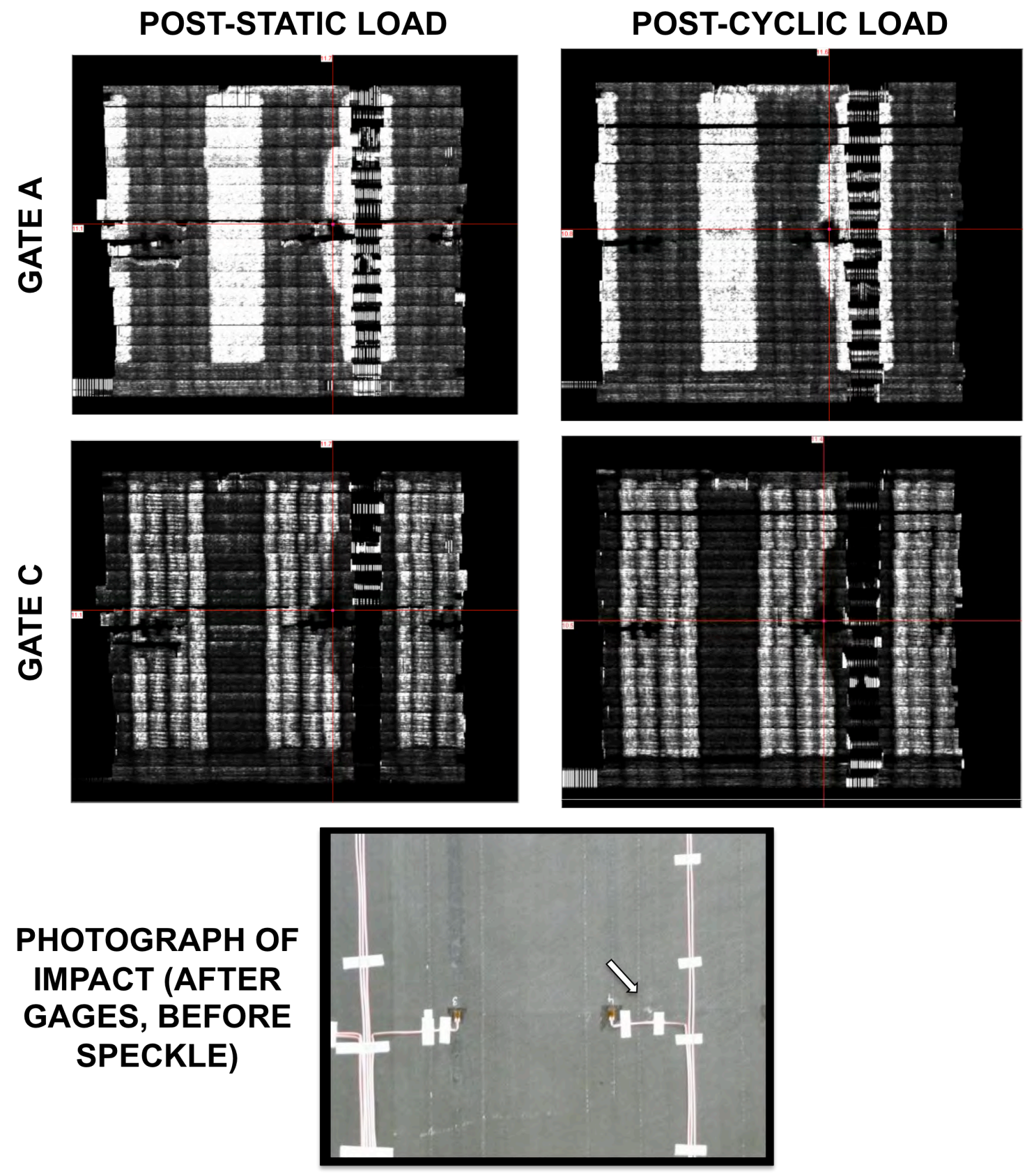

FIGURE 5. C-scan results comparing state of the panel after compressive static loading to design limit load with the condition after an additional twenty cycles of loading. No growth of the delamination under the stringer flange is observed. The photograph in the bottom panel shows the locations of wires, tape and gages, and the point of impact is indicated by an arrow. 